(2) Open Access Full Text Article

ORIGINAL RESEARCH

\title{
Improving Tolerance and Compliance with Topical Immunomodulators Using Micro-Emulsion Lipid Layer Artificial Tears
}

This article was published in the following Dove Press journal: Clinical Ophthalmology

\author{
Alice T Epitropoulos (D) \\ Anthony Therattil (D) ${ }^{2}$ \\ Laura M Periman ${ }^{3}$ \\ Eric D Rosenberg ${ }^{4}$ \\ 'Ophthalmic Surgeons \& Consultants of \\ Ohio, The Eye Center of Columbus, \\ Department of Ophthalmology, The \\ Ohio State University Wexner Medical \\ Center, Columbus, OH, USA; ${ }^{2} \mathrm{New}$ York \\ Medical College, School of Medicine, \\ Valhalla, NY, USA; ${ }^{3}$ Periman Eye Institute, \\ Seattle, WA, USA; ${ }^{4}$ Weill-Cornell Medical \\ College, Department of Ophthalmology, \\ New York, NY, USA
}

Purpose: To investigate the efficacy of a micro-emulsion (ME) lipid layer artificial tear in improving tolerance of immunomodulator eye drops for the treatment of dry eye disease.

Patients and Methods: A total of 33 patients with previously diagnosed dry eye disease were given the micro-emulsion lipid layer artificial tear in conjunction with either lifitegrast or cyclosporine. Patients were queried on their tolerance of the regimen by reporting VAS scores before starting the adjunctive eye drop, immediately after starting, and 2-3 weeks later. Tolerance was statistically compared over time and with respect to previous medication compliance, timing of the adjunctive eye drop, age, gender, and ethnicity.

Results: Across all patients, the VAS pre-treatment score $(6.8 \pm 0.6)$ was significantly higher than both the VAS 1-day post ME lipid tear instillation time point $(3.0 \pm 0.7)$ (post hoc Bonferroni, $\mathrm{p}<0.001)$ and the VAS $2-3$-week post instillation time point $(1.7 \pm 0.7)$ (post hoc Bonferroni, $\mathrm{p}<0.001$ ), with the mean VAS score improving over time (post hoc Bonferroni, $\mathrm{p}<0.028$ ). Average VAS scores did not vary with respect to specific medical therapy or the timing of instillation of this artificial tear. Both the "at-risk" and "conversion" groups independently had significant improvements at both 1-day and 2-3-week time points compared to baseline.

Conclusion: The micro-emulsion lipid layer artificial tear was effective as an adjunctive eye drop to improve tolerance of lifitegrast and cyclosporine for patients with dry eye disease who were at risk of failing or had previously failed immunomodulatory therapy.

Keywords: dry eye disease, cyclosporine, lifitegrast, artificial tears

\section{Introduction}

The efficacy of topical ocular pharmacotherapy depends on patients' adherence and compliance with the prescribed treatment regimen. It is well established that patient compliance with prescribed topical ophthalmic drops is poor and can be a major impediment to effective treatment. This may be due to a combination of factors including burning or discomfort with instillation of drops, physical limitations (ie poor dexterity, tremor) or patients forgetting to instill them. ${ }^{1,2}$

In certain conditions such as glaucoma, the cost of non-compliance can be high with possible progressive vision loss and eventual blindness. ${ }^{3-5}$ In other conditions such as dry eye disease (DED), non-compliance can diminish patients' quality of vision, productivity, quality of life, and increase frustration with continuing symptoms.

Complaints of dry eye are one of the most common reasons that patients see their eye care practitioner. ${ }^{6-9}$ DED represents a significant burden on our public health care
Correspondence: Alice T Epitropoulos Ophthalmic Surgeons \& Consultants of

Ohio at the Eye Center of Columbus, 262

Neil Ave \#430, Columbus, Ohio 43215

Tel +| 6|4-22I-7464

Email EyesMD33@gmail.com 
system, ${ }^{8,9}$ with the potential to affect daily activities, mental health and quality of life. Dry eye represents a complex, multifactorial disease of the ocular surface that may present with a multitude of ocular symptoms and signs. Pathophysiologically, the tear film instability may be associated with loss of homeostasis, a hyperosmolar environment, ocular surface inflammation, and/or neurosensory abnormality. ${ }^{10}$ Although the pathogenesis of DED has yet to be fully elucidated, the condition presents as a selfperpetuating cycle of inflammation. During this process, immune cells migrate to the ocular surface and promote a pro-inflammatory response producing a myriad of signs and/or symptoms characteristic of this condition. ${ }^{11}$

While many subtypes of DED exist, the 2 major classes that form the continuum are aqueous tear-deficient dry eye (ADDE) disease and evaporative dry eye (EDE) disease. ${ }^{12}$ Most DED falls within the EDE category, however pathologies can often be mixed. ${ }^{10}$ Expectedly, with no single reliable test to diagnose DED, clinicians continue to rely on a multitude of ancillary diagnostics, such as fluorescein and lissamine staining of the cornea and conjunctiva, meibomian gland imaging and expressibility, Schirmer testing, tear breakup time (TBUT), matrix metalloproteinase 9 (MMP-9), and tear osmolarity, to guide therapy. Reducing inflammation of the ocular surface is one of the primary goals in treating DED. It is widely recognized that inflammation has a significant role in the pathophysiology of dry eye resulting in ocular surface disruption and symptoms of irritation. ${ }^{10,13}$ A number of anti-inflammatory treatments are in use for the management of DED. Management to restore the ocular surface to normal homeostasis will depend on the type and severity of DED. Clinicians continue to rely on a combination of management algorithms to control the disease process. ${ }^{10,14}$ In the United States, two commonly prescribed drugs utilized to suppress ocular inflammation include lifitegrast ophthalmic solution 5.0\% (Xiidra; Shire US Inc, Lexington, MA; Dublin, Ireland), which received approval from the US Food and Drug Administration (FDA) in 2016 and cyclosporine ophthalmic emulsion 0.05\% (Restasis; Allergan, Madison, NJ; Dublin, Ireland), approved by the FDA in 2003. ${ }^{15,16}$ A cyclosporine ophthalmic solution $0.09 \%$ delivered with nanomicellar technology was approved by the FDA in $2018 .{ }^{17}$

Lifitegrast $5.0 \%$ is a lymphocyte function-associated antigen 1 (LFA-1) antagonist designed to block the interaction of intercellular adhesion molecule 1 (ICAM-1) and LFA-1. ${ }^{18}$ LFA-1 is an integrin receptor found on the surface of $\mathrm{T}$ cells; ICAM-1 is the binding partner of the integrin receptor LFA-1. By blocking this interaction, lifitegrast is thought to inhibit T-cell activation and migration to the ocular surface as well as secretion of multiple proinflammatory cytokines such as interferon gamma, interleukin (IL)-1 $\beta$, and tumor necrosis factor alpha. ${ }^{19-21}$

Cyclosporine A $0.05 \%$ is another unique immunomodulating agent which suppresses inflammation by binding to cyclophilins. This action inhibits the activation of calcineurin - a calcium-dependent phosphate - thereby preventing phosphorylation of the nuclear factor of activated $\mathrm{T}$ cells (cytoplasmic 1), and in turn reducing IL-2 levels while suppressing T-cell activation. ${ }^{22}$

Although lifitegrast and cyclosporine are proven to be highly effective medications, intolerance to these topical drops has been a significant barrier to therapy. With multiple studies citing intolerance and risk of non-compliance or discontinuation (rates from 2.5 to $60 \%$ ) with these drops due to instillation site burning, pain, and irritation, the efficacy of treatment remains limited by its continued use. $^{23-29}$ This is consistent with other studies that have shown a significant percentage of patients using topical drops, in general, are non-compliant with dosing or discontinue the drops altogether. ${ }^{4,30}$

Both drugs require a consistent commitment on behalf of the patient, as DED symptomatology may not improve until 1-3 months after initiation of therapy. However, the well-reported adverse effects of cyclosporine and lifitegrast can make this commitment difficult. Sall et al found that $25 \%$ of patients using cyclosporine $0.05 \%$ experienced at least one adverse effect, the most common of which was burning and stinging. ${ }^{23}$ Meanwhile, a lifitegrast study by Donnenfeld et al found that more than half of the study population reported ocular side effects including burning or discomfort upon instillation and dysgeusia, while $8.2 \%$ reported to be noncompliant while on lifitegrast. ${ }^{28}$ During the OPUS-2 trial, $6.4 \%$ (or 23 patients out of 359) of patients in the lifitegrast group discontinued the medication because of adverse ocular events, ${ }^{27}$ while in the OPUS- 3 trial $4.8 \%$ (or 17 out of 357) of patients discontinued the medication, most often due to ocular irritation and instillation site reaction. ${ }^{26}$ These findings coupled with the known prevalence of DED reveal that there is a very large population of DED patients that could discontinue their medication at any time because of undesirable side effects.

Patients who are started on cyclosporine or lifitegrast are often simultaneously placed on short course of topical steroid drops in an attempt to reduce or alleviate the 
undesired burning or irritation associated with these drops. Long-term use of corticosteroids for treatment of patients with DED are typically not used in clinical practice for DED due to potential side effects such as glaucoma, ocular infection, corneal thinning, and/or the formation of cataracts. $^{31}$ Alternatively, patients experiencing burning and irritation associated with prescription drops may be started on adjunctive artificial tears, but this has been shown to provide insufficient relief leading to noncompliance. ${ }^{28}$

Therefore, patients affected by these adverse effects endure the ocular discomfort, are non-compliant, or discontinue their recommended prescription drops. This noncompliance in patients with DED can further diminish patient's quality of vision, quality of life and productivity, and increase frustration with continuing symptoms. Additionally, an unstable tear film and hyperosmolarity due to inadequately treated DED can adversely affect surgical outcomes by interfering with the accuracy of biometry and intraocular lens implant (IOL) power calculations $^{32}$ and ultimately visual outcomes.

The difficulty in finding a safe, long-term adjunctive eye drop to improve tolerance and prevent non-compliance with either cyclosporine or lifitegrast remains challenging. The number of people suffering from DED is significant, with prevalence in the US reported as high as $14.6 \%$ and even higher in other parts of the world. ${ }^{12}$ The prevalence is likely even higher given that most studies reporting these statistics only consider older adults. Given the prevalence of DED and the prominent usage of cyclosporine and lifitegrast, an effective adjunctive option to improve tolerance and compliance rates would be a welcome addition to the treatment algorithm. To date, there has been no long-term adjunctive drop that has been shown to be effective in reducing the discomfort associated with these prescription eye drops.

Micro-emulsion (ME) lipid layer artificial tears (Rohto Dry-Aid; The Mentholatum Company, Orchard Park, NY) with active ingredients Povidone $0.68 \%$ and propylene glycol $0.3 \%$ as lubricants have a purported cooling effect on the ocular surface (via the inactive ingredient menthol). In a previous study by Torkildsen et al, Rohto Dry-Aid was compared to another artificial tear product for the treatment of DED. ${ }^{33}$ The results show that Rohto DryAid may provide longer lasting symptom relief from dry eye, as the group taking this tear product experienced overall greater relief, although not always statistically significant, from discomfort associated with visual tasking activities and daily diaries. ${ }^{33}$ Furthermore, other studies recommend the investigation of lipid-containing emulsions in "real-world" settings for diagnosing and treating DED as it may stabilize the tear film and synergistically aid in the signs and symptoms. ${ }^{34}$ There are no known or reported adverse effects associated with Rohto Dry-Aid usage.

Given the positive outcomes and the reported soothing effect of Rohto Dry-Aid on the ocular surface, it is reasonable to hypothesize that using ME lipid layer artificial tears in conjunction with cyclosporine or lifitegrast may improve the adverse effects (stinging, burning and irritation) of these medications and increase patient tolerance and compliance.

\section{Patients and Methods}

\section{Selection Procedures}

This single center, prospective, non-randomized, longitudinal case study included patients with dry eye disease at Ophthalmic Surgeons and Consultants of Ohio (Columbus, Ohio, USA) from July of 2018 to July of 2019. Patients were either using, or discontinued and restarted lifitegrast or cyclosporine ophthalmic drops (collectively referred to as immunomodulators) after at least a 4-week course. A total of 33 patients were enrolled. Patients meeting all inclusion and exclusion criteria and who read and signed the study consent and Patient Authorization for Use and Release of Health and Research Study Information forms (US Health Insurance Portability and Accountability Act) were recruited into the study. The study adhered to the tenets of the Declaration of Helsinki and was approved by the Mt. Carmel Institutional Review Board.

All enrolled patients were over the age of 18 and had a previous diagnosis of dry eye disease. Patients were categorized into 2 groups. The first group included patients that were using either lifitegrast or cyclosporine but were bothered by burning, stinging or irritation associated with these prescription drops. They were considered the "at risk" group because they were at risk of discontinuing their medication due to intolerance. The second group, referred to as the "conversion" group, had a history of being on an immunomodulator but were discontinued due to intolerance and were restarted on the immunomodulator with the addition of the ME lipid tear. All patients enrolled stated they used adjunctive artificial tears in addition to their immunomodulator.

Patients rated the burning, stinging and irritation associated with their immunomodulator using the visual analog scale (VAS) from 0 to $100 \mathrm{~mm}$ at baseline. The VAS is 
a frequently used method to assess pain intensity. ${ }^{35} \mathrm{~A}$ rating of at least $40 \mathrm{~mm}$ is used commonly (although this can vary some) as inclusion criteria in other published reports investigating dry eye disease. ${ }^{27,36}$ Patients who rated their discomfort associated with the immunomodulator as $40 \mathrm{~mm}$ or higher were included in the study. Seventeen patients with $\geq$ $40 \mathrm{~mm}$ VAS ratings from burning, irritation or stinging from the immunomodulator comprised the "at-risk" group. Sixteen patients comprised the "conversion" group, in which intolerance had caused these patients to discontinue either lifitegrast or cyclosporine after at least a 4-week course. Exclusion criteria included those who had contraindications to treatment with lifitegrast or cyclosporine, current eye infection or severe inflammation, history of eye injury, herpes infection of the eye or eyelid, or patients with an ocular surface abnormality that may affect the integrity of the cornea or tear film.

\section{Methods}

All evaluations were performed by a single surgeon (A.E.) and the results of the study were based on the subjective VAS scores from the patient based on the discomfort associated with their immunomodulator. The mean age of the patients was 69.3 years \pm 4.2 (SD) (range 36 to 86 years). Each patient had a pre-treatment examination that was based on the surgeon's standard of care and in accordance with the TFOS DEWS II management algorithm. ${ }^{14}$ All patients were asked to rate the severity of stinging, burning or ocular irritation associated with their immunomodulator using a VAS pain score that ranged from 0 to 100 . VAS scores were reported at baseline, prior to combination treatment (immunomodulator and ME lipid-layer artificial tears), immediately after the combination treatment, and 14-21 days following combination treatment.

Thus, for the "at-risk" group, VAS results were documented while on the immunomodulator alone (prior to initiating the addition of the Rohto Dry-Aid), 1 day after adding the adjunctive eye drop, and then 14-21 days following the combination treatment. For the "conversion" group, VAS scores were documented when they were on their immunomodulator prior to discontinuing, 1 day after restarting their immunomodulator together with the adjunctive ME lipid tears, and 14-21 days following the combination treatment. Furthermore, the instillation of ME lipid layer artificial tears was randomized, using a random number generated list, into two categories; 1) utilization prior to instillation of the immunomodulator or 2) following instillation of the immunomodulator. Patients were instructed to instill the drops 5 minutes apart in their assigned order twice per day for the duration of the study. ${ }^{37}$ In addition, patients were queried on the duration of symptoms, age, gender, ethnicity, and current or prior treatment with lifitegrast or cyclosporine.

\section{Statistical Analysis}

The data were analyzed using SPSS version 20.0 (IBM Corporation, Summers, NY). The appropriate test was selected for each data type. All analysis was conducted at the 0.05 alpha level with two-tailed $p$ values reported. Between eye correlations were considered, and the authors identified and utilized the correct statistical methods appropriate for correlated ocular outcome.

\section{Results}

This study included 66 eyes of 33 patients (26 women, 7 men). Table 1 shows the demographic data of the included patients. There was an unequal proportion of females to males in this study (z-score, $\mathrm{p}<0.001$ ); however, gender was independent of medication used $(\mathrm{p}=0.547)$, previous medication compliance $(\mathrm{p}=0.171)$, and order of eye drop instillation ( $\mathrm{p}=0.403$ ). Additionally, there was no significant difference in proportion between the at-risk vs conversion group [ie those who were currently on an immunomodulator but bothered by side effects $(n=17)$ vs those previously intolerant to the immunomodulator and restarted their medication $(n=16)]$ (chi-squared test, $p=0.862$ ). There was also no statistical difference with respect to the dry eye immunomodulator medication used (lifitegrast $\mathrm{n}=22$, cyclosporine $\mathrm{n}=11$, chi-squared test $\mathrm{p}=0.056$ ), and whether the $\mathrm{ME}$ lipid layer artificial tears were instilled 5-minutes prior to, or after instillation of their immunomodulator $(n=19, n=14$, respectively, chi-squared $\mathrm{p}=0.384$ ). Similarly, there was no difference in the average age by gender (females 71.5 vs males 75, Mann-Whitney, $p=0.143$ ); however, the average age of $69.3 \pm 4.2$ years was not normally distributed (Shapiro-Wilk $\mathrm{p}=0.019$ ).

Across all enrolled patients, the VAS scores showed unequal mean values at the three time points recorded (ANOVA, $p<0.001)$. The VAS pre-treatment score $(6.8 \pm$ $0.6)$ was significantly higher than the VAS 1-day post ME lipid layer artificial tears instillation time point $(3.0 \pm 0.7)$ (post hoc Bonferroni, $\mathrm{p}<0.001)$ and the VAS $2-3$ week post instillation time point $(1.7 \pm 0.7)$ (post hoc Bonferroni, $\mathrm{p}<0.001$ ); furthermore, the mean VAS score was also noted to improve over time with ME lipid layer artificial tear use (post hoc Bonferroni, $p<0.028$ ) (Figure 1). The pre-treatment VAS 
Table I Demographic Data of Study Patients

\begin{tabular}{|c|c|c|c|c|c|}
\hline \multirow[t]{2}{*}{ Parameters } & \multicolumn{3}{|c|}{ Sex (\%) } & \multirow{2}{*}{$\begin{array}{c}\text { Mean Age } \\
(y) \pm \text { SD }\end{array}$} & \multirow[t]{2}{*}{ P-value } \\
\hline & Male & Female & P-value & & \\
\hline \multicolumn{6}{|l|}{$\begin{array}{l}\text { Medication } \\
\text { used }\end{array}$} \\
\hline Cyclosporine & 27.3 & 72.7 & $0.547^{*}$ & $73.6 \pm 4.2$ & $0.137^{\circ}$ \\
\hline Lifitegrast & 18.2 & 81.8 & & $67.1 \pm 5.9$ & \\
\hline \multicolumn{6}{|l|}{$\begin{array}{l}\text { Timing of } \\
\text { Rohto use }\end{array}$} \\
\hline Before & 26.3 & 73.7 & $0.403 *$ & $69.7 \pm 6.8$ & $0.866^{\circ}$ \\
\hline After & 14.3 & 85.7 & & $69.0 \pm 5.8$ & \\
\hline \multicolumn{6}{|l|}{$\begin{array}{l}\text { DED } \\
\text { medication } \\
\text { status }\end{array}$} \\
\hline $\begin{array}{l}\text { At-risk } \\
\text { group }\end{array}$ & 11.8 & 88.2 & $0.171 *$ & $69.7 \pm 6.7$ & $0.843^{\circ}$ \\
\hline $\begin{array}{l}\text { Conversion } \\
\text { group }\end{array}$ & 31.2 & 68.8 & & $68.9 \pm 5.8$ & \\
\hline
\end{tabular}

Notes: $*$ Chi-squared test, ${ }^{\circ} t$-test. Demographic data demonstrates that there were no statistical differences between males and females with regard to which medication they used, the order in which they used the medication or if they had stopped using the medication previously. Also, there were no significant differences in age between subjects based on the aforementioned factors.

score was found to be uniformly distributed (KolmogorovSmirnov, $\mathrm{p}=0.571$ ), and expectantly non-uniformly distributed at 1-day post-treatment (Kolmogorov-Smirnov, p = 0.028 ) and at 2-3 weeks post-treatment (KolmogorovSmirnov, $\mathrm{p}<0.001$ ).

A sub-analysis revealed that the average VAS scores do not vary across medical therapy or the timing of the ME lipid layer artificial tear application (Table 2). When comparing VAS means of patients in the at-risk group to those in the conversion group there was no statistical difference in statistical mean at the pre-treatment $(6.5 \pm 0.9$ vs $7.2 \pm 0.9$,

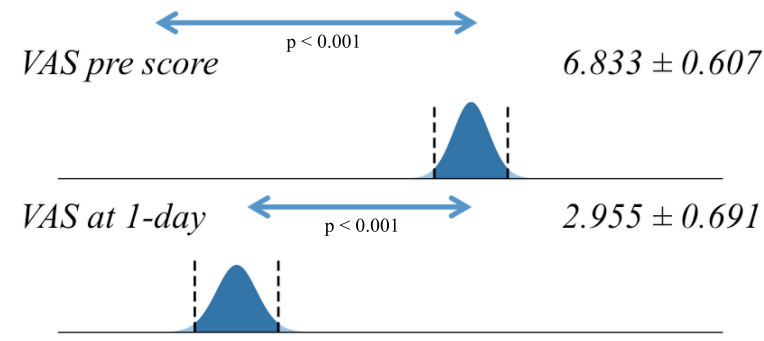

VAS at 2-3 wks

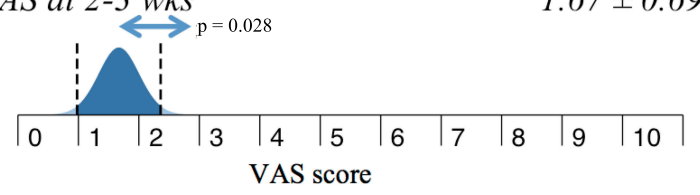

Figure I Change in VAS scores. Mean VAS score differences across all patients and between time points, pre-treatment vs $2-3$ week $(\mathrm{p}<0.00 \mathrm{I})$; pre-treatment vs I-day $(p<0.00 I)$; I-day vs $2-3$ week $(p=0.028)$.

$t$-test $\mathrm{p}=0.255)$ or at the 1 -day post-treatment time points $(2.7 \pm 1.0$ vs $3.2 \pm 1.1, t$-test $\mathrm{p}=0.459)$. There was, however, a statistically significant difference between these two groups at the $2-3$ week time point $(1.0 \pm 0.7$ vs $2.3 \pm 1.2$, $t$-test $\mathrm{p}=0.050)$. For patients in the at-risk group, the VAS scores (ANOVA, $p<0.001$ ) reflected a mean improvement at each of the subsequent time points recorded (post hoc Bonferroni, $\mathrm{p}<0.001$ and $\mathrm{p}=0.005$ ). With respect to patients in the conversion group, the VAS scores (ANOVA, $\mathrm{p}<0.001$ ) reflected a mean improvement from baseline to either 1-day (post hoc Bonferroni, $\mathrm{p}<0.001$ ) or 2-3 week (post hoc Bonferroni, $\mathrm{p}<0.001$ ) time points, however, there was no improvement in the mean VAS score (post hoc Bonferroni, $\mathrm{p}=0.264$ ) when examining between the 1-day to the 2-3 week time points (Figure 2).

Table 2 VAS Score Sub-Analysis

\begin{tabular}{|c|c|c|c|c|c|c|}
\hline Parameters & VAS Prescore \pm SD & P-value & VAS at I-Day \pm SD & P-value & VAS at $2-3$ Wks \pm SD & P-value \\
\hline $\begin{array}{l}\text { Medication used } \\
\text { Cyclosporine } \\
\text { Lifitegrast }\end{array}$ & $\begin{array}{l}6.6 \pm 1.3 \\
7.0 \pm 0.7\end{array}$ & $0.573 *$ & $\begin{array}{l}2.9 \pm 1.5 \\
3.0 \pm 0.8\end{array}$ & $0.926 *$ & $\begin{array}{l}2.1 \pm 1.7 \\
1.5 \pm 0.7\end{array}$ & $0.388 *$ \\
\hline $\begin{array}{l}\text { DED medication status } \\
\text { At-risk group } \\
\text { Conversion group }\end{array}$ & $\begin{array}{l}6.5 \pm 0.9 \\
7.2 \pm 0.9\end{array}$ & $0.255^{*}$ & $\begin{array}{l}2.7 \pm 1.0 \\
3.2 \pm 1.1\end{array}$ & $0.459 *$ & $\begin{array}{l}1.0 \pm 0.7 \\
2.3 \pm 1.3\end{array}$ & $0.050 *$ \\
\hline $\begin{array}{l}\text { Timing of Rohto use } \\
\text { Before } \\
\text { After }\end{array}$ & $\begin{array}{l}6.7 \pm 0.9 \\
7.0 \pm 1.0\end{array}$ & $0.712 *$ & $\begin{array}{l}3.2 \pm 0.9 \\
2.7 \pm 1.2\end{array}$ & $0.494 *$ & $\begin{array}{l}1.8 \pm 1.0 \\
1.5 \pm 1.0\end{array}$ & $0.611 *$ \\
\hline
\end{tabular}

Notes: *t-test. Analysis demonstrates that VAS scores were significantly different at the $2-3$ week timepoint in subjects who never stopped taking medication (at-risk group) versus those that did previously stop (conversion group). There was also a statistically significant improvement $(p<0.00 \mathrm{I}$ ) in VAS scores from baseline to the I-day and $2-3$ week time points across all parameters, regardless of medical therapy, timing of Rohto use, or whether patients were in the at-risk versus conversion group. 
A
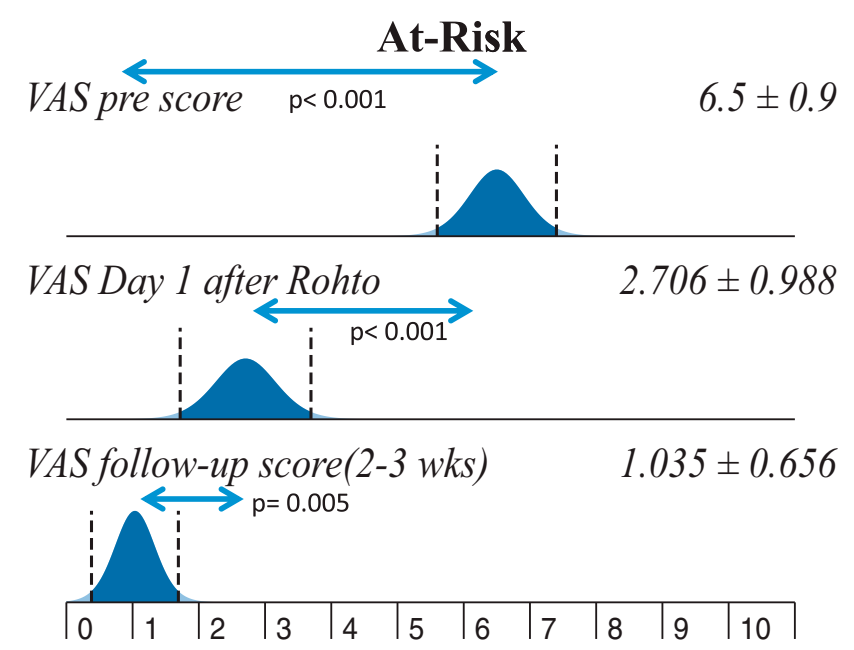

B
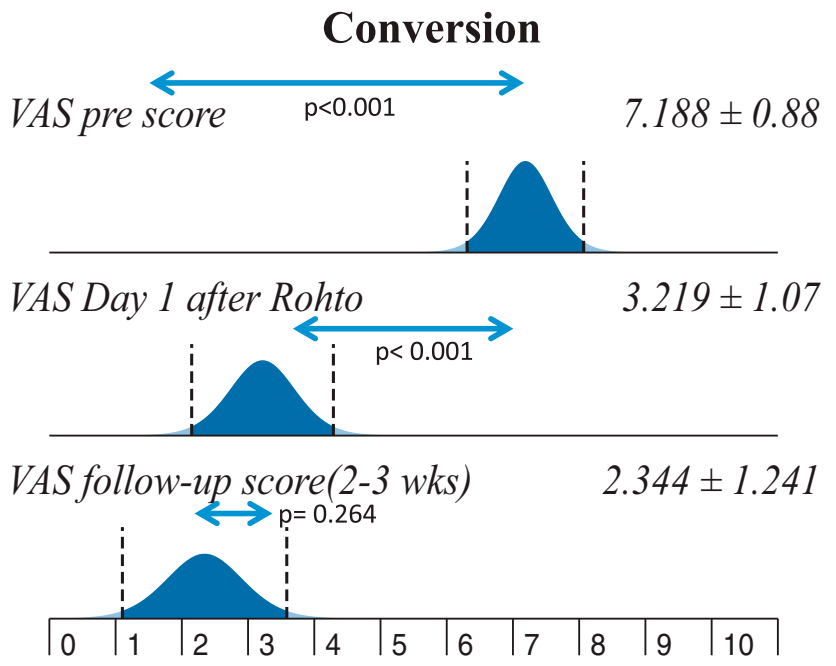

Figure 2 VAS scores by subject group. VAS scores over time for subjects in the atrisk (A) and conversion (B) groups.

At baseline, there was no significant difference in age of the patients with respect to dry eye immunomodulator used ( $t$-test, $\mathrm{p}=0.137)$; previous compliance of dry eye treatment ( $t$-test, $\mathrm{p}=0.843)$; or administration of the ME lipid layer artificial tear ( 5 minutes prior to or 5 minutes after immunomodulator) ( $t$-test, $\mathrm{p}=0.866)$. There was a positive correlation between age and VAS 1-day post ME lipid layer artificial tears instillation time point, with younger patients appearing to symptomatically respond quicker to the effects of the ME lipid later artificial tears. This correlation waned at the 2-3 week time point.

\section{Discussion}

Dry eye disease symptoms represent the most common reason patients visit their eye care practitioner, yet many patients may not achieve a satisfactory outcome due to the condition not being diagnosed or poor tolerance and subsequent noncompliance with common prescription medications to treat the disease. This may result in frustration and persistence or worsening of symptoms. In a retrospective study, Gologorsky and Greenstein found that patients seek a second opinion out of desire to confirm the diagnosis or in reaction to previous adverse experiences such as perceived treatment failure or complications (ie drug side effects). ${ }^{38}$ Furthermore, the lack of a known proven and safe adjunctive medication to assist with these hurdles has remained a major barrier to successfully treating DED. In this paper, we investigate the use of an adjunctive ME lipid layer artificial tear eye drop (Rohto Dry-Aid) in a small group of dry eye patients having difficulty tolerating immunomodulators.

Overall, these results provide evidence that using the ME lipid layer artificial tear in conjunction with an immunomodulatory medication for DED improves the subjective symptomology and tolerance of these two drug classes. An overwhelming majority (94\%) of patients reported improved VAS scores using the adjunctive ME tear along with the immunomodulator the following day, with all (100\%) enrolled patients reporting improved VAS scores by the 2-3 week follow up. The patients based the VAS score on tolerability of immunomodulators with the adjunctive drop. At no time during the study did any patient discontinue the adjunctive or primary therapy and no adverse events were recorded. Additionally, improvement in patient-reported VAS scores continued to improve over the time course of this study, suggesting a timedependent logarithmic effect, plateauing slightly earlier for known previously failed treatment patients.

The effectiveness of ME lipid layer artificial tears in those that had previously discontinued their immunomodulator (conversion group) illustrates that adding these drops can be beneficial for patients who might be more sensitive to the ocular side-effects of lifitegrast $5.0 \%$ and cyclosporine $0.05 \%$. Although this group of patients may not have experienced as large of a subjective effect as the group who were bothered by but remained on their immunomodulator (at-risk group), there was still a profound and statistically significant improvement in symptoms at each time point. More importantly, those patients who previously failed 
therapy were once again able to tolerate and remain on their immunomodulator. With this new evidence, physicians can expect to give their patients a more comfortable therapeutic regimen, leading to more consistent medication compliance and better control of DED.

There was no significant difference in tolerability between patients using lifitegrast $5.0 \%$ and cyclosporine $0.05 \%$, suggesting that ME lipid layer artificial tears can be used effectively with both major classes of immunemodulating medications used for DED. Although twice as many lifitegrast patients were enrolled compared to cyclosporine patients $(\mathrm{p}=0.056)$, sub-analyses revealed no statistical differences between the two groups across all dependent variables.

Expectedly, patient age was not normally distributed, as there is a well-established correlation between age and $\mathrm{DED}^{12,39,40}$ and may constitute a limitation in the current study. Additional limitations include that over $90 \%$ of the voluntarily registered study population was Caucasian, $79 \%$ was female, and that this was a single surgeon, single-site study. This study's female predominant population is consistent with the real-world global prevalence of DED in women estimated at 1.33 to 1.74 times higher. ${ }^{41}$ Lastly, based on the duration and controls of this study, we cannot yet determine whether further improvement would be seen past 2-3 weeks with additional studies needed.

The mechanisms behind the observed effect have yet to be elucidated, however the authors postulate three possible mechanisms: 1) lubrication effects of the active ingredients $^{42}$ (Table 3) may reduce the stinging, burning and irritation associated with the instillation of immunomodulators; 2) reduced evaporative rate of the ME lipid layer tears (possibly improved Tear Break Up Time-TBUT, but this was not measured); and 3) corneal nerve modulating effect through the inactive ingredient, menthol. The lubrication effects may improve friction symptoms with blinking and the ME lipid layer drops may improve the evaporative rate of the tears (TBUT), leaving the corneal epithelium less

Table 3 Ingredients in Rohto Dry-Aid ${ }^{\dagger}$

\begin{tabular}{|l|l|}
\hline Active & Povidone $\mathbf{0 . 6 8 \%}$, Propylene glycol $\mathbf{0 . 3 \%}$ \\
\hline Inactive & $\begin{array}{l}\text { Boric acid, Menthol, Calcium chloride, Edetate disodium, } \\
\text { Magnesium sulfate, PEG-10 castor oil, Poloxamer, } \\
\text { Polyaminopropyl biguanide, Polyoxyl stearate, Purified } \\
\text { water, Sesame oil, Sodium borate }\end{array}$ \\
\hline
\end{tabular}

Notes: ${ }^{\dagger}$ Ingredients reported from National Institutes of Health US National Library of Medicine. ${ }^{42}$ exposed to inflammation-inducing desiccating stress in between blinks. A corneal nerve sensory modulation mechanism may lie in the menthol inactive ingredient. In fact, menthol is commonly perceived to deliver a cooling sensation which may promote ocular comfort through agonist activity specifically on an evaporation-induced temperature sensor channel, Transient Receptor Potential Melastatin 8, also known as TRPM8. ${ }^{43}$

TRP channels are a superfamily of cation cellular sensors with a wide distribution in many species' neuronal and nonneuronal tissues with roles in sensation as well as inflammation, infection and immunity. ${ }^{43,44}$ Dysfunction of corneal nerve afferent signals in response to temperature (evaporative load) and hyperosmolarity in DED has been described and TRPM8 and TRPV1 have been implicated. ${ }^{45}$ Additionally, basal tear secretion and maintenance of ocular surface wetness is maintained by TRPM8-dependent cold thermoreceptors of the cornea as demonstrated in a murine TRPM8 knock out model. ${ }^{46}$ Both TRPV1 and TRPM8 are implicated in DED. ${ }^{47}$ Hyperosmolarity can activate TRPV1 and increase pro-inflammatory cytokines ${ }^{48}$ and TRPM8 activation leads to a decline in TRPV1-mediated inflammatory activity. $^{49}$

Low-dose menthol activates TRPM8 without nociceptive behaviors and has been shown to increase lacrimal gland output in a rodent model. ${ }^{50}$ In a recent human trial, dry eye disease subjects had higher sensitivity to cold compared to normal controls and administration of Rohto Hydra $0.01 \%$ menthol drops was associated with higher mean "cooling scores" in patients with DED for less than 10 years. ${ }^{51}$ An anti-inflammatory role for TRPM8 has been described by blocking the TRPV1-dependent release of the neuroinflammatory peptide calcitonin-gene-related peptide (CGRP) in a mouse colitis and human colitis cell culture model. ${ }^{52}$ CGRP is well implicated in corneal inflammation and neuropathic pain. ${ }^{53}$ While the TRPV1 and TRPA1 channels act as nociceptive and inflammation potentiators in cutaneous neurogenic inflammation, ${ }^{54}$ the interplay has not yet been described in ocular neurogenic inflammation.

A notable limitation to this study is that it was an openlabel study. Such studies are subject to potential observer bias as the examiner may subconsciously encourage a favorable result that would agree with the hypothesis being tested. Additionally, if the examiner is favoring a particular result or conveying certain expectations then the subject may be more likely to produce these results (Pygmalion effect). Although the data were not masked to the examiner, the patients recorded their VAS scores 
independently at home, reducing potential biases that may affect patients' subjective scoring.

In conclusion, patients treated by lifitegrast or cyclosporine often experience burning, stinging and irritation upon instillation, occasionally leading to discontinuation or noncompliance. This study revealed that a microemulsion lipid layer artificial tear (Rohto Dry-Aid) used as an adjunctive eye drop, evaluated with VAS scoring, can improve the tolerance of lifitegrast and cyclosporine for patients with DED who are at risk or have previously failed immunomodulatory therapy. Future studies evaluating the effects of this artificial tear over a longer duration are needed to determine if it is a suitable long-term option for this population. These studies, ideally masked, could evaluate longer term patient symptom scores, tear volume, tear stability/tear break-up time (TBUT), osmolarity and point of care inflammatory biomarkers like MMP-9 will help to further explore the potential neural, tear volume and inflammation modulating effects of Rohto Dry-Aid lubricating ME drops with menthol.

\section{Acknowledgments}

Mentholatum provided product for the study. Thank you to Dr. Craig Czyz, DO, for help with this study and the IRB.

\section{Disclosure}

E.D.R received travel compensation from Mentholatum. A.T.E is speaker/consultant for Allergan and Novartis, outside the submitted work. A.T reports grants from Orbit Biomedical and Heidelberg Engineering, outside the submitted work. L.M.P is speaker/consultant for Allergan, Alcon, Novartis, and Sun, outside the submitted work. The authors report no other conflicts of interest in this work.

\section{References}

1. An JA, Kasner O, Samek DA, Levesque V. Evaluation of eyedrop administration by inexperienced patients after cataract surgery. J Cataract Refract Surg. 2014;40(11):1857-1861. doi:10.1016/j. jcrs.2014.02.037

2. Van Buskirk EM. The compliance factor. Am J Ophthalmol. 1986;101 (5):609-610. doi:10.1016/0002-9394(86)90954-2

3. Lacey J, Cate H, Broadway DC. Barriers to adherence with glaucoma medications: a qualitative research study. Eye (Lond). 2009;23 (4):924-932. doi:10.1038/eye.2008.103

4. Tsai JC, McClure CA, Ramos SE, Schlundt DG, Pichert JW. Compliance barriers in glaucoma: a systematic classification. J Glaucoma. 2003;12 (5):393-398. doi:10.1097/00061198-200310000-00001

5. Friedman DS, Hahn SR, Gelb L, et al. Doctor-patient communication, health-related beliefs, and adherence in glaucoma results from the Glaucoma Adherence and Persistency Study. Ophthalmology. 2008;115(8):1320-1327. doi:10.1016/j.ophtha.2007.11.023
6. O'Brien PD, Collum LM. Dry eye: diagnosis and current treatment strategies. Curr Allergy Asthma Rep. 2004;4(4):314-319. doi:10.1007/s11882-004-0077-2

7. Doughty MJ, Fonn D, Richter D, Simpson T, Caffery B, Gordon K. A patient questionnaire approach to estimating the prevalence of dry eye symptoms in patients presenting to optometric practices across Canada. Optom Vis Sci. 1997;74(8):624-631. doi:10.1097/00006324199708000-00023

8. Li M, Gong L, Chapin WJ, Zhu M. Assessment of vision-related quality of life in dry eye patients. Invest Ophthalmol Vis Sci. 2012;53 (9):5722-5727. doi:10.1167/iovs.11-9094

9. McDonald M, Patel DA, Keith MS, Snedecor SJ. Economic and Humanistic Burden of Dry Eye Disease in Europe, North America, and Asia: a Systematic Literature Review. Ocul Surf. 2016;14 (2):144-167. doi:10.1016/j.jtos.2015.11.002

10. Craig JP, Nichols KK, Akpek EK, et al. TFOS DEWS II Definition and Classification Report. Ocul Surf. 2017;15(3):276-283. doi:10.1016/j.jtos.2017.05.008

11. Stevenson W, Chauhan SK, Dana R. Dry eye disease: an immune-mediated ocular surface disorder. Arch Ophthalmol. 2012;130(1):90-100.

12. Janine AS. The epidemiology of dry eye disease: report of the Epidemiology Subcommittee of the International Dry Eye WorkShop (2007). Ocul Surf. 2007;5(2):93-107. doi:10.1016/ S1542-0124(12)70082-4

13. Hessen M, Akpek EK. Dry eye: an inflammatory ocular disease. J Ophthalmic Vis Res. 2014;9(2):240-250.

14. Jones L, Downie LE, Korb D, et al. TFOS DEWS II Management and Therapy Report. Ocul Surf. 2017;15(3):575-628. doi:10.1016/j. jtos.2017.05.006

15. Lifitegrast ophthalmic solution [Prescribing information]. 2016. Available from: https://www.accessdata.fda.gov. Accessed June 11, 2020.

16. Cyclosporine ophthalmic solution 0.5\% [Prescribing information]. 2003. Available from: https://www.accessdata.fda.gov. Accessed June 11, 2020.

17. Cyclosporine ophthalmic solution $0.09 \%$ [Drug information]. Available from: https://www.accessdata.fda.gov. Accessed June 11, 2020.

18. Perez VL, Pflugfelder SC, Zhang S, Shojaei A, Haque R. Lifitegrast, a Novel Integrin Antagonist for Treatment of Dry Eye Disease. Ocul Surf. 2016;14(2):207-215. doi:10.1016/j.jtos.2016.01.001

19. Gao J, Morgan G, Tieu D, et al. ICAM-1 expression predisposes ocular tissues to immune-based inflammation in dry eye patients and Sjogrens syndrome-like MRL/lpr mice. Exp Eye Res. 2004;78 (4):823-835. doi:10.1016/j.exer.2003.10.024

20. Murphy CJ, Bentley E, Miller PE, et al. The pharmacologic assessment of a novel lymphocyte function-associated antigen-1 antagonist (SAR 1118) for the treatment of keratoconjunctivitis sicca in dogs. Invest Ophthalmol Vis Sci. 2011;52(6):3174-3180. doi:10.1167/iovs.09-5078

21. Sun Y, Zhang R, Gadek TR, O'Neill CA, Pearlman E. Corneal inflammation is inhibited by the LFA-1 antagonist, lifitegrast (SAR 1118). J Ocul Pharmacol Ther. 2013;29(4):395-402. doi:10.1089/ jop. 2012.0102

22. Matsuda S, Koyasu S. Mechanisms of action of cyclosporine. Immunopharmacology. 2000;47(2-3):119-125. doi:10.1016/S01623109(00)00192-2

23. Sall K, Stevenson OD, Mundorf TK, Reis BL. Two multicenter, randomized studies of the efficacy and safety of cyclosporine ophthalmic emulsion in moderate to severe dry eye disease. CsA Phase 3 Study Group. Ophthalmology. 2000;107(4):631-639. doi:10.1016/S0161-6420(99)00176-1

24. Perry HD, Solomon R, Donnenfeld ED, et al. Evaluation of topical cyclosporine for the treatment of dry eye disease. Arch Ophthalmol. 2008;126(8):1046-1050. doi:10.1001/archopht.126.8.1046

25. Byun YS, Rho CR, Cho K, Choi JA, Na KS, Joo CK. Cyclosporine $0.05 \%$ ophthalmic emulsion for dry eye in Korea: a prospective, multicenter, open-label, surveillance study. Korean J Ophthalmol. 2011;25(6):369-374. doi:10.3341/kjo.2011.25.6.369 
26. Holland EJ, Luchs J, Karpecki PM, et al. Lifitegrast for the Treatment of Dry Eye Disease: results of a Phase III, Randomized, Double-Masked, Placebo-Controlled Trial (OPUS-3). Ophthalmology. 2017;124(1):53-60. doi:10.1016/j.ophtha.2016.09.025

27. Tauber J, Karpecki P, Latkany R, et al. Lifitegrast Ophthalmic Solution 5.0\% versus Placebo for Treatment of Dry Eye Disease: results of the Randomized Phase III OPUS-2 Study. Ophthalmology. 2015;122(12):2423-2431. doi:10.1016/j.ophtha.2015.08.001

28. Donnenfeld ED, Karpecki PM, Majmudar PA, et al. Safety of Lifitegrast Ophthalmic Solution $5.0 \%$ in Patients With Dry Eye Disease: a 1-Year, Multicenter, Randomized, Placebo-Controlled Study. Cornea. 2016;35(6):741-748. doi:10.1097/ICO.00000000000 00803

29. Mah F, Milner M, Yiu S, Donnenfeld E, Conway TM, Hollander DA. PERSIST: physician's Evaluation of Restasis((R)) Satisfaction in Second Trial of topical cyclosporine ophthalmic emulsion $0.05 \%$ for dry eye: a retrospective review. Clin Ophthalmol. 2012;6: 1971-1976. doi:10.2147/OPTH.S30261

30. Osterberg L, Blaschke T. Adherence to medication. $N$ Engl J Med. 2005;353(5):487-497. doi:10.1056/NEJMra050100

31. Lollett IV, Galor A. Dry eye syndrome: developments and lifitegrast in perspective. Clin Ophthalmol. 2018;12:125-139. doi:10.2147/ OPTH.S126668

32. Epitropoulos AT, Matossian C, Berdy GJ, Malhotra RP, Potvin R. Effect of tear osmolarity on repeatability of keratometry for cataract surgery planning. J Cataract Refract Surg. 2015;41(8):1672-1677. doi:10.1016/j.jcrs.2015.01.016

33. Torkildsen G, Brujic M, Cooper MS, et al. Evaluation of a new artificial tear formulation for the management of tear film stability and visual function in patients with dry eye. Clin Ophthalmol. 2017;11:1883-1889. doi:10.2147/OPTH.S144369

34. Chen M, Miki M, Lin S, Yung Choi S. Sodium Fluorescein Staining of the Cornea for the Diagnosis of Dry Eye: a Comparison of Three Eye Solutions. Med Hypothesis Discov Innov Ophthalmol. 2017;6 (4):105-109.

35. Eli Eliav RHG. Methods for Pain Assessment. In: Yair Sharav RB, editor. Orofacial Pain and Headache. 45-56. 2008.

36. Wirta DL, Torkildsen GL, Moreira HR, et al. A Clinical Phase II Study to Assess Efficacy, Safety, and Tolerability of Waterfree Cyclosporine Formulation for Treatment of Dry Eye Disease. Ophthalmology. 2019;126(6):792-800. doi:10.1016/j.ophtha.2019.01. 024

37. Prum BE Jr, Rosenberg LF, Gedde SJ, et al. Primary Open-Angle Glaucoma Preferred Practice Pattern((R)) Guidelines. Ophthalmology. 2016;123(1):P41-P111. doi:10.1016/j.ophtha.2015.10.053

38. Gologorsky D, Greenstein SH. Retrospective analysis of patients self-referred to comprehensive ophthalmology seeking second opinions. Clin Ophthalmol. 2013;7:1099-1102. doi:10.2147/OPTH. S46448

39. Moss SE, Klein R, Klein BE. Prevalence of and risk factors for dry eye syndrome. Arch Ophthalmol. 2000;118(9):1264-1268. doi:10.10 01/archopht.118.9.1264
40. Schaumberg DA, Sullivan DA, Buring JE, Dana MR. Prevalence of dry eye syndrome among US women. Am J Ophthalmol. 2003;136 (2):318-326. doi:10.1016/S0002-9394(03)00218-6

41. Stapleton F, Alves M, Bunya VY, et al. TFOS DEWS II Epidemiology Report. Ocul Surf. 2017;15(3):334-365. doi:10.1016/ j.jtos.2017.05.003

42. ROHTO DRY-AID- povidone, propylene glycol liquid [Drug Information]. Available from: https://dailymed.nlm.nih.gov. Accessed June 11, 2020. Accessed May 19, 2020.

43. Zheng J. Molecular mechanism of TRP channels. Compr Physiol. 2013;3(1):221-242. doi:10.1002/cphy.c120001

44. Fernandes ES, Fernandes MA, Keeble JE. The functions of TRPA1 and TRPV1: moving away from sensory nerves. $\mathrm{Br} J$ Pharmacol. 2012;166(2):510-521. doi:10.1111/j.1476-5381.2012.01851.x

45. Hirata H, Meng ID. Cold-sensitive corneal afferents respond to a variety of ocular stimuli central to tear production: implications for dry eye disease. Invest Ophthalmol Vis Sci. 2010;51 (8):3969-3976. doi:10.1167/iovs.09-4744

46. Parra A, Madrid R, Echevarria D, et al. Ocular surface wetness is regulated by TRPM8-dependent cold thermoreceptors of the cornea. Nat Med. 2010;16(12):1396-1399. doi:10.1038/nm.2264

47. Eguchi H, Hiura A, Nakagawa H, Kusaka S, Shimomura Y. Corneal Nerve Fiber Structure, Its Role in Corneal Function, and Its Changes in Corneal Diseases. Biomed Res Int. 2017;2017:3242649. doi:10. $1155 / 2017 / 3242649$

48. Hua X, Su Z, Deng R, Lin J, Li DQ, Pflugfelder SC. Effects of L-carnitine, erythritol and betaine on pro-inflammatory markers in primary human corneal epithelial cells exposed to hyperosmotic stress. Curr Eye Res. 2015;40(7):657-667. doi:10.3109/02713683. 2014.957776

49. Khajavi N, Mergler S, Biebermann H. 3-Iodothyronamine, a Novel Endogenous Modulator of Transient Receptor Potential Melastatin 8? Front Endocrinol (Lausanne). 2017;8:198. doi:10.3389/fendo.2017. 00198

50. Robbins A, Kurose M, Winterson BJ, Meng ID. Menthol activation of corneal cool cells induces TRPM8-mediated lacrimation but not nociceptive responses in rodents. Invest Ophthalmol Vis Sci. 2012;53 (11):7034-7042. doi:10.1167/iovs.12-10025

51. Corcoran P, Hollander DA, Ousler GW 3rd, et al. Dynamic Sensitivity of Corneal TRPM8 Receptors to Menthol Instillation in Dry Eye Versus Normal Subjects. J Ocul Pharmacol Ther. 2017;33 (9):686-692. doi:10.1089/jop.2017.0050

52. Ramachandran R, Hyun E, Zhao L, et al. TRPM8 activation attenuates inflammatory responses in mouse models of colitis. Proc Natl Acad Sci US A. 2013;110(18):7476-7481. doi:10.1073/pnas.1217431110

53. Galor A, Moein HR, Lee C, et al. Neuropathic pain and dry eye. Ocul Surf. 2018;16(1):31-44. doi:10.1016/j.jtos.2017.10.001

54. Gouin O, L'Herondelle K, Lebonvallet N, et al. TRPV1 and TRPA1 in cutaneous neurogenic and chronic inflammation: pro-inflammatory response induced by their activation and their sensitization. Protein Cell. 2017;8(9):644-661. doi:10.1007/s13238-017-0395-5
Clinical Ophthalmology

\section{Publish your work in this journal}

Clinical Ophthalmology is an international, peer-reviewed journal covering all subspecialties within ophthalmology. Key topics include: Optometry; Visual science; Pharmacology and drug therapy in eye diseases; Basic Sciences; Primary and Secondary eye care; Patient Safety and Quality of Care Improvements. This journal is indexed on PubMed
Central and CAS, and is the official journal of The Society of Clinical Ophthalmology (SCO). The manuscript management system is completely online and includes a very quick and fair peer-review system, which is all easy to use. Visit http://www.dovepress.com/ testimonials.php to read real quotes from published authors. 